\title{
EXPERIMENTAL ANALYSIS FOR THERMAL PERFORMANCE OF A VAPOR CHAMBER APPLIED TO HIGH-PERFORMANCE SERVERS
}

\author{
Rong-Tsu Wang \\ Department of Marketing and Logistics, Vanung University, Tao-Yuan, Taiwan, R.O.C. \\ Jung-Chang Wang \\ Department of Marine Engineering, National Taiwan Ocean University, Keelung, Taiwan, R.O.C., \\ jcwang@mail.ntou.edu.tw \\ Tien-Li Chang \\ Department of Mechatronic Technology, National Taiwan Normal University, Taipei, Taiwan, R.O.C.
}

Follow this and additional works at: https://jmstt.ntou.edu.tw/journal

Part of the Engineering Commons

\section{Recommended Citation}

Wang, Rong-Tsu; Wang, Jung-Chang; and Chang, Tien-Li (2011) "EXPERIMENTAL ANALYSIS FOR THERMAL PERFORMANCE OF A VAPOR CHAMBER APPLIED TO HIGH-PERFORMANCE SERVERS," Journal of Marine Science and Technology. Vol. 19: Iss. 4, Article 3.

DOI: $10.51400 / 2709-6998.2175$

Available at: https://jmstt.ntou.edu.tw/journal/vol19/iss4/3

This Research Article is brought to you for free and open access by Journal of Marine Science and Technology. It has been accepted for inclusion in Journal of Marine Science and Technology by an authorized editor of Journal of Marine Science and Technology. 


\section{EXPERIMENTAL ANALYSIS FOR THERMAL PERFORMANCE OF A VAPOR}

CHAMBER APPLIED TO HIGH-PERFORMANCE SERVERS

\section{Acknowledgements}

The authors gratefully acknowledgment the financial support from NTOU and NSC 97-2218-E-019-003 for the present study. 


\title{
EXPERIMENTAL ANALYSIS FOR THERMAL PERFORMANCE OF A VAPOR CHAMBER APPLIED TO HIGH-PERFORMANCE SERVERS
}

\author{
Rong-Tsu Wang*, Jung-Chang Wang**, and Tien-Li Chang***
}

Key words: vapor chamber, VCTM V1.0, high-performance server, effective thermal conductivity, dimensional analysis.

\begin{abstract}
This article conducts experimental analysis using the window program VCTM V1.0 to investigate the thermal performance of a vapor chamber and then applies the findings to a high-performance server. The experimental method is derived from a novel formula for the effective thermal conductivity of a vapor chamber and functions to calculate its thermal performance. Results show that the maximum heat flux is over $100 \mathrm{~W} / \mathrm{cm}^{2}$, and the effective thermal conductivity is many times higher than the copper heat spreaders. The maximum effective thermal conductivity is $870 \mathrm{~W} / \mathrm{m}^{\circ} \mathrm{C}$ according to the novel formula, and comparing it with the experimental value, the calculating error is no more than $\pm 3 \%$.
\end{abstract}

\section{INTRODUCTION}

High temperature is a major reason for malfunctions or shortened life spans occurring in electronic components. Power dissipation above 120 Watts per chip is projected for high-performance application in electronic devices within recent years. High-performance computer servers are especially required in service fields and leading-edge research where computing capabilities must be high-speed, exhibit high reliability, and offer large-scale transmission. The maximum limited temperature found in silicon chips in electronic components is $120^{\circ} \mathrm{C}$, with a normal operating temperature of under $70^{\circ} \mathrm{C}$. The reliability of electronic components drops by $10 \%$ for each increase of $2{ }^{\circ} \mathrm{C}$ in normal operating temperature. Technical development related to cooling with the application of

Paper submitted 12/15/09; revised 03/08/10; accepted 03/23/10. Author for correspondence: Jung-Chang Wang (e-mail: jcwang@mail.ntou.edu.tw).

*Department of Marketing and Logistics, Vanung University, Tao-Yuan, Taiwan, R.O.C.

**Department of Marine Engineering, National Taiwan Ocean University, Keelung, Taiwan, R.O.C.

***Department of Mechatronic Technology, National Taiwan Normal University, Taipei, Taiwan, R.O.C. two-phase flow heat transfer assembly to thermal modules has advanced and a heat pipe-based thermal module is one of the best choices. Wang [7] utilized superposition method to analyze an aluminum heat sink with two and four embedded heat pipes $6 \mathrm{~mm}$ in diameter; they can carry $36 \%$ and $48 \%$ of the total dissipated heat capacity from CPU and the total thermal resistance is under $0.24^{\circ} \mathrm{C} / \mathrm{W}$. Wang et al. [9] also developed a windows program coded with Microsoft ${ }^{\circledR}$ Visual Basic $^{\mathrm{TM}} 6.0$ and used to calculate the thermal performance of a heat sink with embedded heat pipes. The program found that the optimum heights of the embedded heat pipes inserted through fins are $21 \mathrm{~mm}$ and $15 \mathrm{~mm}$ for the two heat pipe sink and four heat pipe sink, respectively. A heat sink featuring heat pipes shows good thermal performance and low manufacturing cost application in servers, PCs, and notebooks [5]. Thus, it is necessary to quickly remove high heat generated by electronic components to maintain a normal operating temperature of under $70^{\circ} \mathrm{C}$. For applications in both smaller and higher performance electronic devices, another flat-plate type heat pipe is widely used as a novel heat dissipater; it is usually called a vapor chamber.

Wei [10] indicated that the integration of a vapor chamber yields further improvement; the cooling performance is improved by $20 \%$, with a $20 \%$ weight reduction application in high-performance servers. For metallic materials as the heat dissipaters, their thermal conductivities have constant values when the operating temperature does not largely vary. The thermal conductivities of pure cooper and aluminum as heat spreaders are $401 \mathrm{~W} / \mathrm{m}^{\circ} \mathrm{C}$ and $237 \mathrm{~W} / \mathrm{m}^{\circ} \mathrm{C}$, respectively, at an operating temperature of $27^{\circ} \mathrm{C}$ [1]. When the operating temperature is $127^{\circ} \mathrm{C}$, they are $393 \mathrm{~W} / \mathrm{m}^{\circ} \mathrm{C}$ and $240 \mathrm{~W} / \mathrm{m}^{\circ} \mathrm{C}$, respectively. The two-phase flow heat transfer device of a vapor chamber has better thermal performance than metallic material in a large footprint heat sink. Lin et al. [6] identified three different wick structures of vapor chambers as heat dissipater application in high performance chips and obtained effective thermal conductivity with $800 \mathrm{~W} / \mathrm{m}^{\circ} \mathrm{C}$ through an experimental method. This value of effective thermal conductivity of the vapor chamber is two times higher than that of pure copper material. Wang [8] replaced a traditional metal base plate with a vapour chamber, a two-phase flow heat transfer module with high heat transfer efficiency, to effectively reduce 
the temperature of heat sources as graphic processing unit (GPU) of smaller area and higher power. The results showed that when the fin height from vapour chamber top to fan bottom area is more than $3 \mathrm{~mm}$ and not more than $8 \mathrm{~mm}$, the vapour chamber-based thermal module can achieve the optimum heat dissipation and the maximum heat flux may exceed $90 \mathrm{~W} / \mathrm{cm}^{2}$. Also, when copper fins are $3 \mathrm{~mm}$ in height, $0.2 \mathrm{~mm}$ in thickness, 53 in number and spaced out $1.0 \mathrm{~mm}$ apart, the optimum total thermal resistance of a vapour chamber-based thermal module is $0.265^{\circ} \mathrm{C} / \mathrm{W}$. Koito et al. [4] found that pure copper material has higher values than that of vapor chamber for weight and thermal stress of an integral heating spreader (IHS). A heat removal capacity of $220 \mathrm{~W} / \mathrm{cm}^{2}$ with a thermal spreading resistance of $0.2{ }^{\circ} \mathrm{C} / \mathrm{W}$ is the vapor chamber heat spreader $[2,3]$. The vapor chamber can reduce the spreading resistances sufficiently by its excellent lateral spreading effect. The effective thermal performance of the vapor chamber has been previously confirmed according to up-to-date research and mass production applications in server systems.

Estimating the effective thermal conductivity of a vapor chamber is very important for getting the thermal performance of the vapor chamber-based thermal module. The objective of this present study is to derive a novel formula for the effective thermal conductivity of a vapor chamber and then develop the window program VCTM V1.0 to rapidly compute its value application in simulating the vapor chamber-based thermal module in the server computer system. This formula is dependent on the characteristics of the vapor chamber and the input power and dimensions of the heat source. A zip-fin heat sink is soldered upon the heat spreader as a thermal module for heat dissipation and tested in a wind tunnel to examine its thermal performance. According to the formula and the program VCTM V1.0 to obtain effective thermal conductivity of the vapor chamber as a heat spreader, there is a numerical value of thermal performance of the thermal module. The comparison with numerical values to experimental data will help us to understand the effectiveness and thermal performance of the vapor chamber and this novel formula is in excellent agreement with experimental results of this study.

\section{METHODOLOGY}

\section{Dimensional Analysis}

In this article, a flat-plate type heat pipe made of $\mathrm{C} 1200$ oxygen-free copper (vapor chamber) soldering folder-fins are discussed, as are the thermal performance and effective thermal conductivity as shown in Fig. 1. Its dimensions are $90 \times$ $90 \times 3.0 \mathrm{~mm}^{3}$, the porosity of the capillary structure in the interior of the cavity is under 0.5 , and the maximum fill-up amount is under $10 \mathrm{~mm}^{3}$. Pure water containing low oxygen content is enclosed as the working fluid and is filled up in the interior of vapor chamber. Its advantages are embodied in its thermal-physics properties, such as extremely high latent heat and thermal conductivity and low viscosity, as well as its nontoxicity and incombustibility. Copper mesh composed of $50 \mu \mathrm{m}$

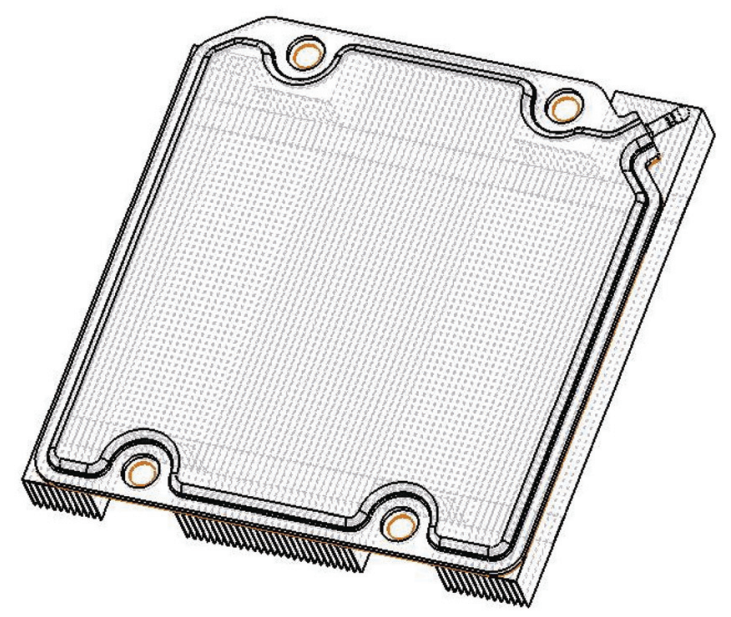

Fig. 1. A vapor chamber with folder-fins.

diameter wire has 100/200 mesh pores and a $2 \mathrm{~mm}$ solid diameter copper cylinder and a supported vacuum and its loading force are used to circulate the working fluid. Its manufacture process utilizes diffusion bounding without any soldering materials. The copper meshes are bonded to the upper, lower, and perimeter of the internal surface to ensure the circulation of the working fluid completely circulates the working fluid. The overall operating principle is defined as follows: at the very beginning, the interior of the vapor chamber is in the vacuum, after the wall face of the cavity absorbing the heat from its source, the working fluid in the interior will be rapidly transformed into vapor under the evaporating or boiling mechanism and fill up the whole interior of the cavity, the resultant vapor will be condensed into liquid by the cooling action resulting from the convection between the fins and fan on the outer wall of the cavity and reflow to the place of the heat source along the capillary structure will occur.

One of the major purposes of this paper is to deduce the thermal performance of the empirical formula of the vapor chamber, and to find out several dimensionless groups for multiple correlated variables based on the systematic dimensional analysis of the [F.L.T.Ө.] in the Buckingham $\Pi$ Theorem, as well as the relationship between dimensionless groups and the effective thermal conductivity. Its theorem is defined as follows: if there are $m$ variables, which are functions of each other in certain physical phenomenon or equation, the dimensional analysis will be changed into i non-dimensional parameters, and $i$, the number of parameters, is derived from the formula $(m-r)=i$, where $r$ represents the number of used dimensions. Reducing $\mathrm{r}$ variables like this can explicitly demonstrate the dimension relation in the physical equation to be analyzed. The most common method for the dimensional analysis is repeating variable methods, its related procedures are as follows: firstly, determine that there are $\mathrm{m}$ variable related functions in certain physical phenomenon or equation, and $r$ basic functions of related variables, and select the socalled repeating variables from all related variables; secondly, 


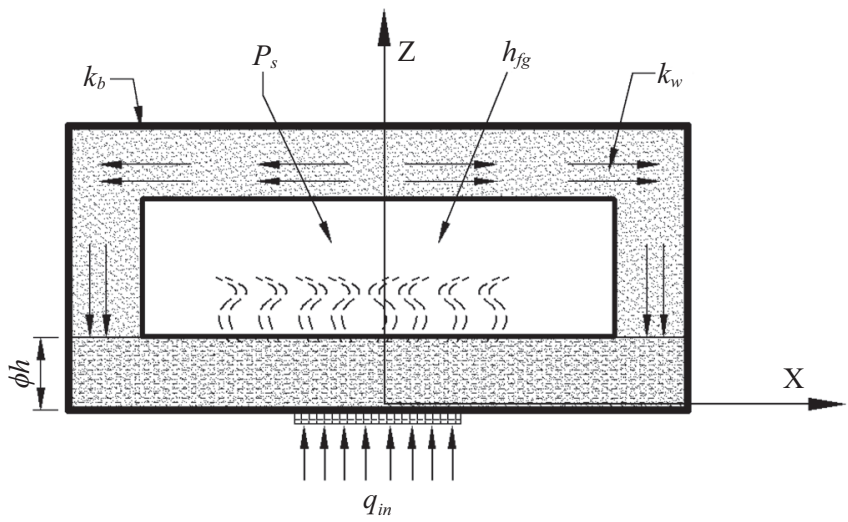

Fig. 2. Related variables of the vapor chamber.

multiply the remainder of i related variables by different-powers of repeating variables one by one to produce i parameters of $\mathrm{Pi}$; finally, determine the powers of related variables to enable all $\mathrm{Pi}$ items to become the non-dimensional parameter groups. The point to choose repeating variables is giving priority to relatively common variables, for which the reason that they will repeatedly occur in Pi variables. If a certain related variable is correlated to other ones, we had better not choose such related variables as the repeated variable. If we can deduce the proper non-dimensional parameter group using the dimensional analysis, the relational expression of the whole functional equation can be effectively deduced by the database of related data inferred from the previously mentioned experimental parameters.

Fig. 2 is the abbreviated drawing of related variables of the vapor chamber to be confirmed in this article, and the equation (1) is the functional expression deduced based on the related variables as shown in Fig. 2. The symbol $k_{\text {eff }}$ in the equation is the value of the effective thermal conductivity of the vapor chamber, the $k_{b}$ is the thermal conductivity of the material the vapor chamber is made of, the symbol $k_{w}$ is the value of the effective thermal conductivity of the wick structure of the vapor chamber, the unit of these thermal conductivities are $\mathrm{W} / \mathrm{m}^{\circ} \mathrm{C}$. The symbol $q_{\text {in }}$ is the heat flux of the dummy heater and its unit is $\mathrm{W} / \mathrm{m}$. The symbol $h_{f g}$ is latent heat of the working fluid which has a unit of $\mathrm{J} / \mathrm{k}$. The $P_{s}$ is the saturated vapor pressure of working fluid with unit of $\mathrm{N} / \mathrm{m}$. The symbol $\mathrm{t}$ is the thickness of the vapor chamber and the symbol $\phi h$ is the height of the working fluid inside the vapor chamber. Their unit is $\mathrm{m}$. The symbol $A$ is the area of the vapor chamber and its unit is $\mathrm{m}^{2}$.

$$
K_{\text {eff }}=\text { Function }\left\{k_{b}, k_{w}, q_{\text {in }}, h_{f g}, P_{s}, t, A, \phi h\right\}
$$

It can be inferred from the equation (1) that there are nine related variables (symbol $\mathrm{m}$ equaling to 9 ), and the following equation (2) can be inferred by making use of the [F.L.T. $\theta$.] system (symbol $r$ equaling to 4 ) to work a dimensional analysis of the various parameters in the above-mentioned equation and combining the analysis result with the Eq. (1).

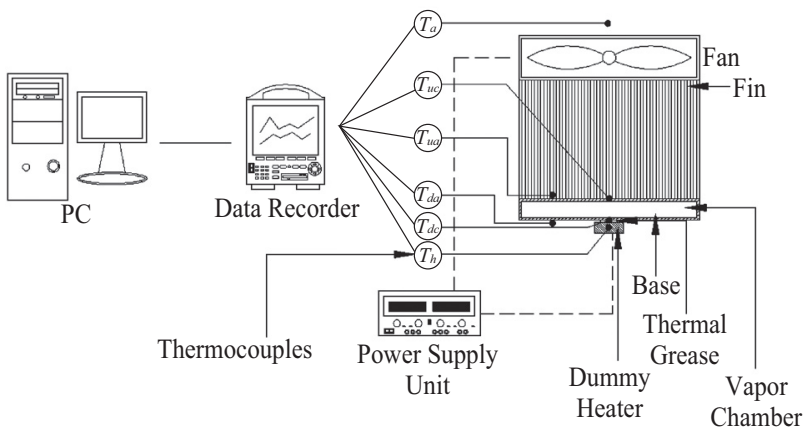

Fig. 3. Experimental testing drawing of the vapor chamber-based thermal module.

$$
\left(\frac{k_{e f f}}{k_{b}}\right)=\alpha \cdot\left(\frac{k_{w}}{k_{b}}\right)^{\beta} \cdot\left(\frac{q_{\text {in }}}{P_{s} \cdot h_{f g}^{0.5}}\right)^{\gamma} \cdot\left(\frac{A}{t^{2}}\right)^{\lambda} \cdot\left(\frac{\phi h}{t}\right)^{\tau}
$$

The $\alpha, \beta, \gamma, \lambda, \tau$ in the equation (2) indicate the constants determined based on the experimental parameters. We can know from the said equation (2) that effective thermal conductivity of the vapor chamber is related to the controlling parameters of the experiment, fill-up number of the working fluid influencing symbol $\phi h$, volume of the cavity influencing symbol $t$, input power and area of the heat source influencing $q_{i n}$, area of the vapor chamber influencing symbol A. Thus, this study is designed to firstly use thermal-performance experiment to determine the thermal performance and related experimental controlling parameters of the vapor chamberbased thermal, and sort them into the database of these experimental data, then combine with equation (2) to obtain the constants of the symbols $\alpha, \beta, \gamma, \lambda, \tau$.

\section{Experimental Procedure}

The experimental methods stated in this paper are mainly aimed at testing the thermal performance of the vapor chamber-based thermal module as shown in Fig. 3. The vapor chamber is assembled with machined fins. The experimental test includes experiments using different fin thicknesses and fin gap sizes. The upper surface of the dummy heater is coated with thermal grease to reduce contact resistance. The dummy heater is connected with to digital power to supply the power required to run a dummy heater and cooling fans. A T-type thermocouple is attached to the upper surface of the dummy heater to measure the temperature $\left(T_{h}\right)$. Ten thermocouples are attached to the center of the lower and upper surfaces of the vapor chamber and eight points along the diagonal of the lower and upper surfaces of the vapor chamber, measuring the temperatures at the center of the lower and upper surfaces of the vapor chamber $\left(T_{d c}, T_{u c}\right)$ and the average temperature of the lower and upper surfaces of the vapor chamber $\left(T_{d a}, T_{u a}\right)$ respectively. A fan is placed on the top of the heat sink to disperse heat through forced convection. A thermocouple is placed on the top of the fan to measure the ambient temperature $\left(T_{a}\right)$ as 
shown in Fig. 4. The measurement error of the power supply is $\pm(0.5 \%+2$ digits $)$. The data recorder is manufactured by Yokogawa Company, data is sampled via thirty channels and an RS232 communication gateway is used to connect with the PC. This device is mainly used to record the temperature values at various thermocouple locations inside thermal modules and the measurement error is $\pm 1 \%$. Type $\mathrm{T}$ thermocouple is used and its measurement error is $\pm 0.5^{\circ} \mathrm{C}$. The maximum error for the thermal resistance is within $\pm 5 \%$.

Eq. (3) indicates the one-dimensional thermal conductivity $\left(k_{z}\right)$, which is the result of the heat flux $q_{\text {in }}$ multiplied by the thickness $(t)$ of the vapor chamber divided by the central temperature $\left(T_{d c}\right)$ on the lower surface minus the $\left(T_{u c}\right)$ on the upper surface. Eq. (4) demonstrates the two-dimensional thermal conductivity $\left(k_{x y d}\right)$, which is the result of the heat flux $q_{\text {in }}$ multiplied by the thickness $(t)$ of the vapor chamber divided by the central temperature $\left(T_{d c}\right)$ on the lower surface minus the mean surface temperature $\left(T_{d a}\right)$. Eq. (5) shows the two-dimensional thermal conductivity $\left(k_{x y u}\right)$, which is the result of the heat flux $q_{\text {in }}$ multiplied by the thickness $(t)$ of the vapor chamber divided by the central temperature $\left(T_{u c}\right)$ on the upper surface minus the mean surface temperature $\left(T_{u a}\right)$. Eq. $(6)$ indicates the three-dimensional thermal conductivity $\left(k_{x y z}\right)$, which is the result of the heat flux $q_{\text {in }}$ multiplied by the thickness $(t)$ of the vapor chamber divided by the mean surface temperature $\left(T_{d a}\right)$ on the lower surface minus the $\left(T_{u a}\right)$ on the upper surface.

$$
\begin{gathered}
k_{z}=q_{i n} \cdot t /\left(T_{d c}-T_{u c}\right) \\
k_{x y d}=q_{i n} \cdot t /\left(T_{d c}-T_{d a}\right) \\
k_{x y u}=q_{i n} \cdot t /\left(T_{u c}-T_{u a}\right) \\
k_{x y z}=q_{i n} \cdot t /\left(T_{d a}-T_{u a}\right)
\end{gathered}
$$

Certain errors exist between the data measured during experiment, value deriving from experimental data, and the actual values due to artificial operation and limitation of the accuracy of the experimental apparatus. For this reason, it is necessary take note of the experimental errors to create confidence in the experiments before analyzing experimental results. The concept of the propagation of error is introduced to calculate experimental error and fundamental functional relations for propagation of error. During the experiment, various items of thermal resistances and thermal conductivities are utilized to analyze the heat transfer characteristics of various parts of the thermal modules. The thermal resistance and thermal conductivity belong to derived variables and includes temperature and heating power, which are measured with experimental instruments. The error of experimental instruments is propa-

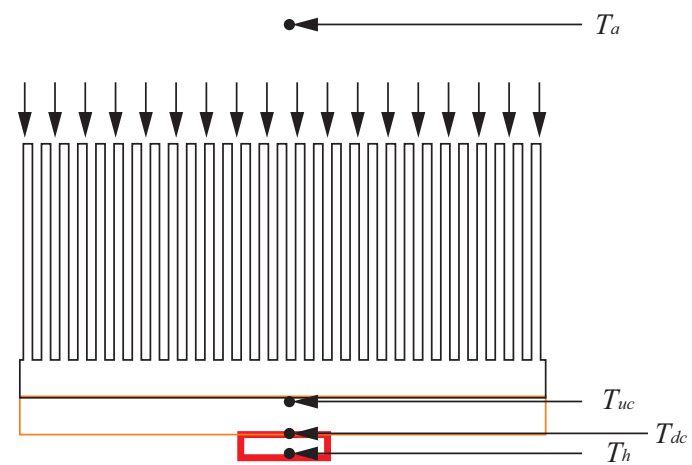

(a)

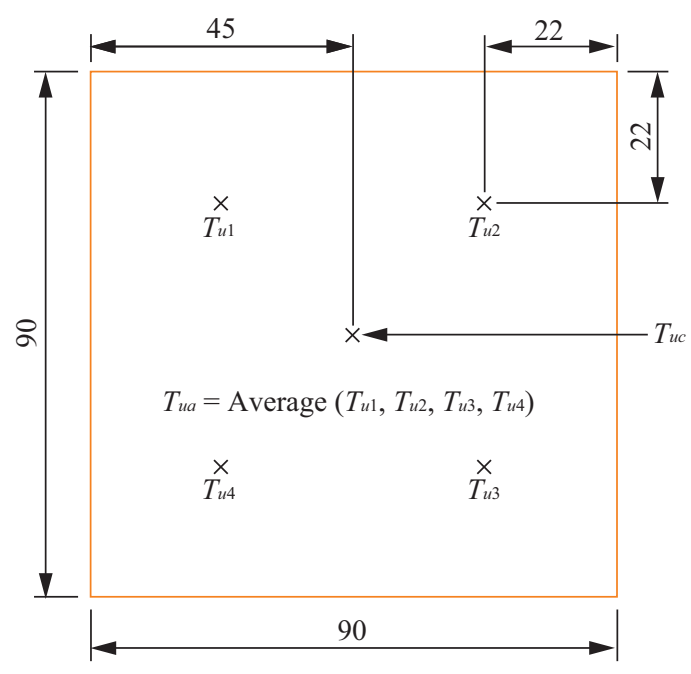

(b)

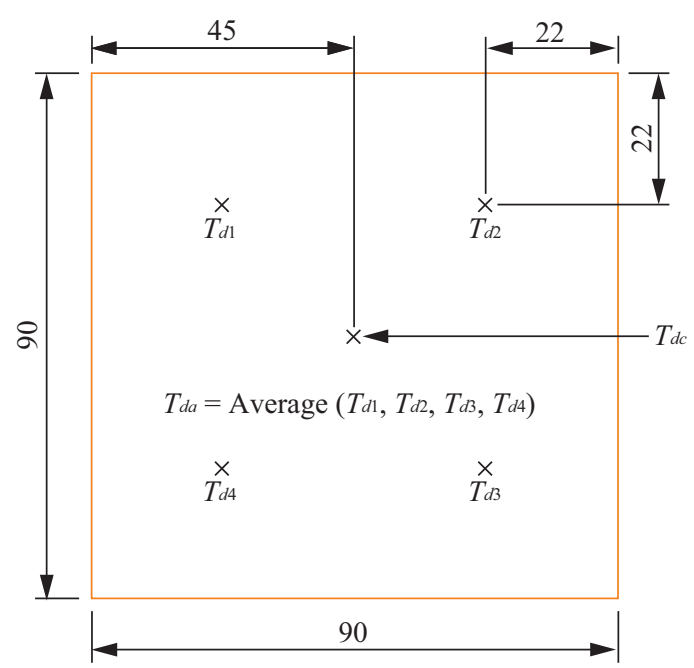

(c)

Fig. 4. (a) Measured temperature points of the vapor chamber, (b) Measured temperature points of the upper surface, (c) Measured temperature points of the lower surface.

gated to the result values during deduction, and thus become the error of thermal resistance and thermal conductivity values. An experimental error is represented with a relative error and 


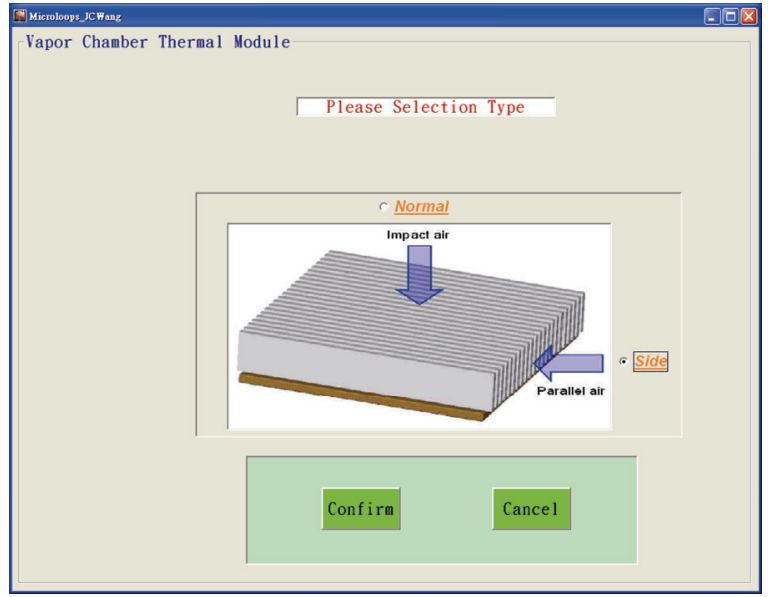

Fig. 5. Selection air direction window.

the maximum relative error of thermal conductivities defined are within $\pm 2.5 \%$ of $k_{z}, \pm 3.7 \%$ of $k_{x y d}, \pm 3.7 \%$ of $k_{x y u}$ and $\pm 4.2 \%$ of $k_{x y z}$.

\section{Window Program Development}

This window program 'VCTM V1.0' was coded with Microsoft $^{\mathbb{R}}$ Visual Basic ${ }^{\mathrm{TM}} 6.0$ and calculated the thermal performance of a vapor chamber-based thermal module. There are parameters that affect its thermal performance, including the dimensions and position of the vapor chamber. Thus, it is very important for the optimum parameters to be selected to achieve the best thermal performance of the vapor chamberbased thermal module. The program contains two main windows. The first is the selection window which is adjusted in the program as the main menu as shown in Fig. 5. In this window, the air direction can be chosen separately. The second window has five main sub-windows. There are four sub-windows of the input parameters for thermal module as shown in Fig. 6. The first sub-window contains the simple parameters of the vapor chamber, including dimensions and thermal performance as shown in Fig. 6(a). Fig. 6(b) shows the second sub-window involving the detailed dimensions of a heat sink. The third and fourth sub-windows are the simple parameters containing the input power of heat source, the materials of the thermal grease and solder, and the performance curve of the fan as shown in Figs. 6(c) and 6(d). All the input parameters required for the study of the window program were given and the window program begins. Later, the program examines the situation upon pressing the calculated icon. The fifth sub-window is the window showing the simulation results. In this sub-window, when the calculate icon is pressed, analysis of the thermal performance of a vapor chamber-based thermal module begins, as is shown in Fig. 7.

\section{RESULTS AND DISCUSSION}

The relationship diagram of effective thermal conductivity of the vapor chamber and heat source power derived from the

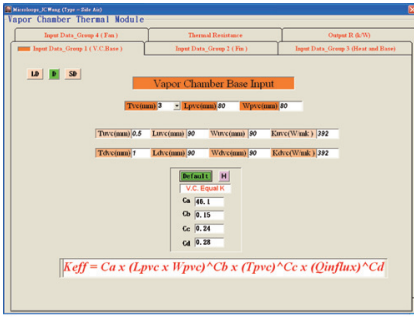

(a)

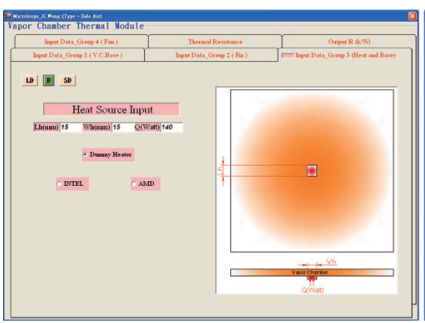

(c)

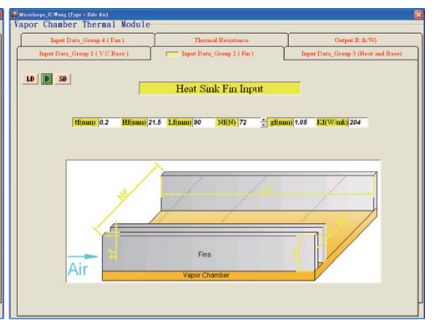

(b)

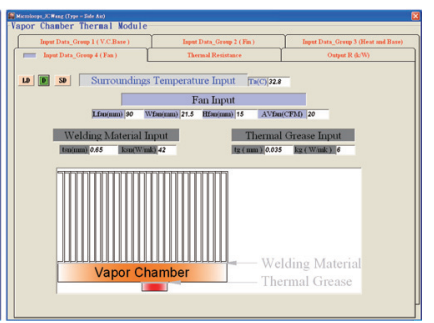

(d)
Fig. 6. Input parameters before operation (a) Dimensions and thermal performance of the vapor chamber, (b) Dimensions and materials of the fins, (c) Dimensions, input power and materials of the heat source, (d) Performance and materials of the fan and welding grease.

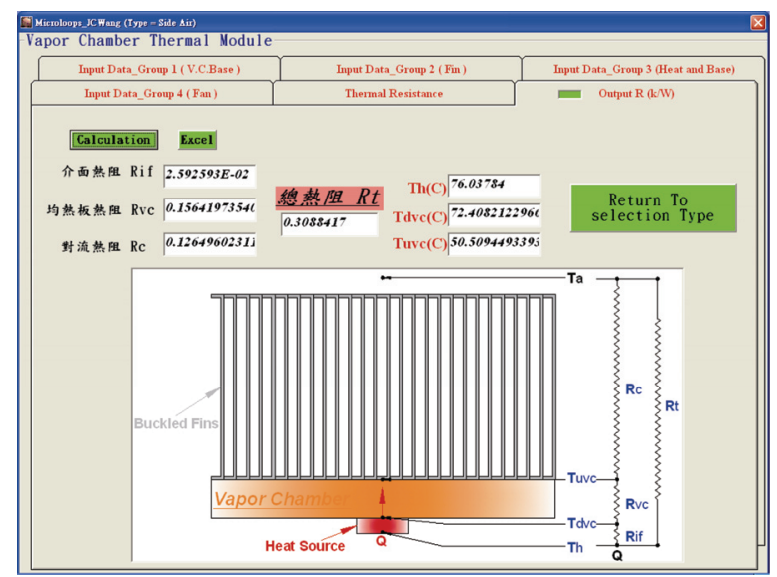

Fig. 7. Main menu of program after operation.

thermal-resistance performance experiment as shown in Fig. 8. The value of one-dimensional thermal conductivity $k_{z}$ and twodimensional thermal conductivity $k_{x y d}$ are all at about 100 $\mathrm{W} / \mathrm{m}^{\circ} \mathrm{C}$ respectively, much smaller than that of pure copper and aluminum materials. Taking the example of one-dimensional thermal resistance, the capillary structure in the interior of the vapor chamber produced very big thermal resistance to render a small value of one-dimensional thermal conductivity $k_{z}$. The small value of two-dimensional thermal conductivity $k_{x y d}$ is due to the thermal-performance below the vapor chamber influenced by the capillary structure. In terms of $k_{x y u}$ and $k_{x y z}$ two- and three-dimensional thermal conductivities, excellent values of thermal conductivity are all above $500 \mathrm{~W} / \mathrm{m}^{\circ} \mathrm{C}$ due to effects of the latent heat arisen from the aqueous phase changing into vapor, which are better than that of pure copper 


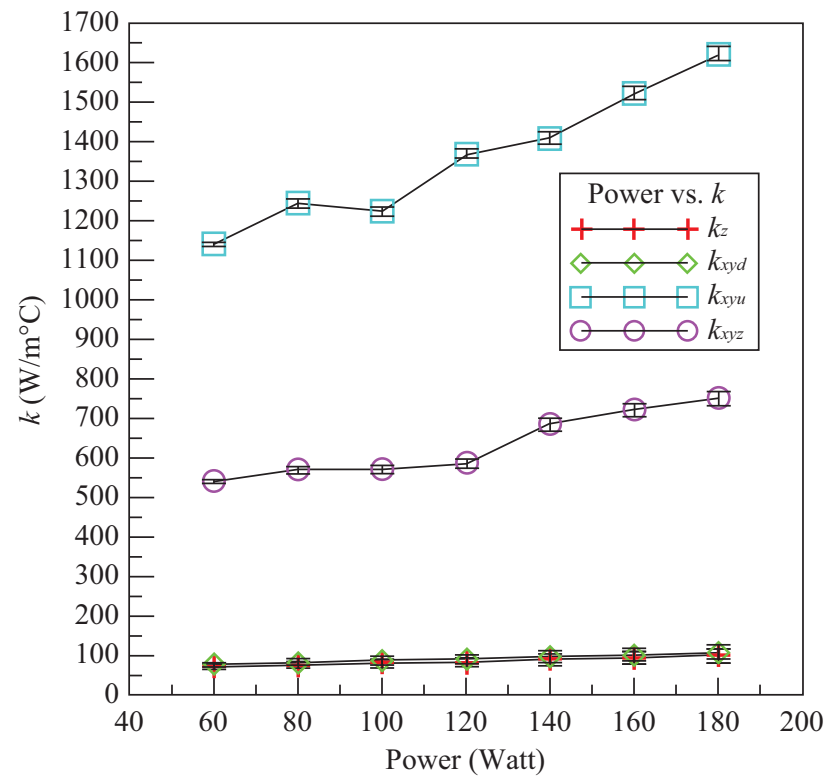

Fig. 8. The relationship between the effective thermal conductivities of the vapor chamber with input power.

and aluminum materials. Three-dimensional thermal conductivity $k_{x y z}$ can be expressed as the value of the effective thermal conductivity of the vapor chamber and replacing the metallic base plate of the vapor chamber-based thermal module can absolutely improve the overall thermal-performance of the thermal module. In summary, all dimensional effective thermal conductivities will rise with the increasing of power of the heat source.

The constants $\alpha, \beta, \gamma, \lambda, \tau$ in Eq. (2) can be deduced by conducting dimensional analysis with thermal-resistance performance experiment, and the formula for effective thermal conductivity coefficients of the vapor chamber can be inferred by combining such constants with known experimental data, as shown in the following formula (7). In the Fig. 9, the relations of the effective thermal conductivity of the vapor chamber under the heat flux of caused by the heat sources are discussed by use of the formula (7). It is the relationship diagram of the heat flux of related heat sources of effective thermal conductivity in the circumstances of $3.0 \mathrm{~mm}$ thickness of the vapor chamber and its area ranging from $100 \times 100 \mathrm{~mm}^{2}$ to $40 \times 40 \mathrm{~mm}^{2}$. We can ascertain that the effective thermal conductivity will increase with the area of the vapor chamber, with a maximum value of $870 \mathrm{~W} / \mathrm{m}^{\circ} \mathrm{C}$. In terms of the vapor chamber with the area of $40 \times 40 \mathrm{~mm}^{2}, 50 \times 50 \mathrm{~mm}^{2}$ and $60 \times$ $60 \mathrm{~mm}^{2}$ and a heat source flux less than $10 \mathrm{~W} / \mathrm{cm}^{2}$, its effective thermal conductivity is less than that of pure copper and aluminum materials. We can ascertain that the overall thickness of the vapor chamber varies inversely as its effective thermal conductivity in the same vacuum chamber space resulting from Eq. (7). This is because the wall thickness increases with the overall thickness of the vapor chamber and its thermal performance varies inversely as the resultant thermal resistance.

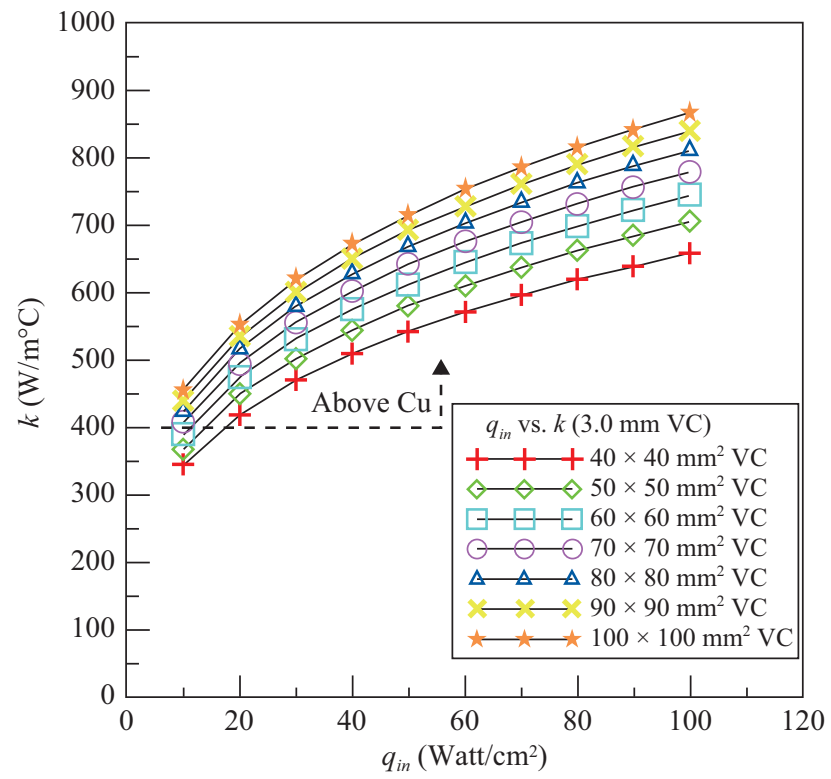

Fig. 9. The relationship between the effective thermal conductivities of $3.00 \mathrm{~mm}$ thickness of vapor chamber with heat flux of the heat source.

$$
k_{e f f}=46.1 \cdot\left(L_{v c} \cdot W_{v c}\right)^{0.15} \cdot\left(t_{v c}\right)^{0.24} \cdot\left(q_{i n}\right)^{0.28}
$$

The stated and proved formula of the effective thermal conductivity of the vapor chamber used as the single solid-phase metallic base plate can be applied in the calculation of the overall thermal performance of thermal module. The comparisons of the total thermal resistance value of vapor chamberbased thermal modules calculated using the VCTM V1.0 and the experimental value from the wind tunnel testing of the actual mass-production goods of the thermal module with the vapor chamber, which is then applied to high-power servers as shown in the Figs. 10 and 11. Fig. 10 shows that the relationship between the total thermal resistances of the vapor chamber thermal module with air volume flow rate at input power 130 Watt. The total thermal resistances of the testing result and the calculation result are $0.213^{\circ} \mathrm{C} / \mathrm{W}$ and $0.19^{\circ} \mathrm{C} / \mathrm{W}$, respectively, at $20 \mathrm{CFM}$. They present maximum error. At 55 CFM, there is minimum error between the total thermal resistances of the testing result and the calculation result. The average error is $4.76 \%$ at 130 Watt.

The relationship between the total thermal resistances of the vapor chamber thermal module with an air volume flow rate at an input power of 210 Watt is shown in Fig. 11. Table 1 illustrates the four folder-fins compared in this article. Symbol F1 is copper material and its fin gap is $1.7 \mathrm{~mm}$. Symbol F2 is copper material and its fin gap is $1.4 \mathrm{~mm}$. Symbol F3 is copper material and its fin gap is $1.0 \mathrm{~mm}$. Symbol F4 is aluminum material and its fin gap is $1.0 \mathrm{~mm}$. The total average error is $2.86 \%$ at 210 Watt. At $20 \mathrm{CFM}$, there is minimum error between the total thermal resistances of testing result and calculation result, which is $0 \%$ at F3. The maximum error 


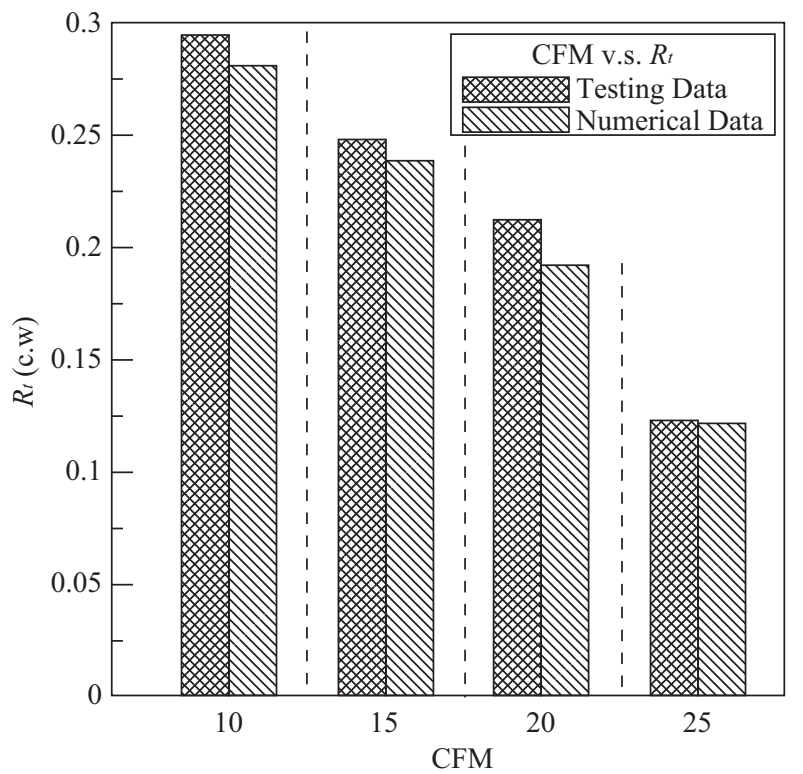

Fig. 10. The relationship between the total thermal resistances of the vapor chamber thermal module with air volume flow rate at input power 130 Watt.

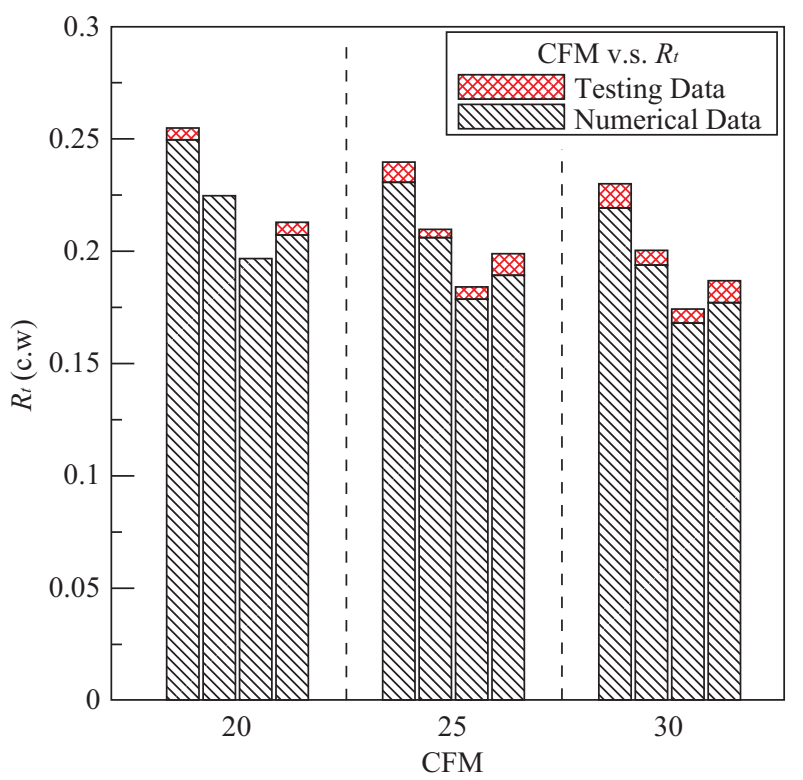

Fig. 11. The relationship between the total thermal resistances of the vapor chamber thermal module with air volume flow rate at input power 210 Watt.

is $5.35 \%$, seen in the aluminum fins at 30 CFM. Taking the example of electronic business thermal-conductivity software of the thermal performance of vapor chamber-based thermal module commercially and calculatedly available, time for calculating and analysis of the single case is at least above one hour. If the calculation of VCTM V1.0 can be finished within one minute, the average error will be under $6 \%$. It is correct to apply the formula (7) for the effective thermal conductivity
Table 1. Types of folder-fins.

\begin{tabular}{|c|c|c|c|c|}
\hline Symbol & F1 & F2 & F3 & F4 \\
\hline Thickness $(\mathrm{mm})$ & 0.3 & 0.3 & 0.3 & 0.3 \\
\hline gap $(\mathrm{mm})$ & 1.7 & 1.4 & 1.0 & 1.0 \\
\hline Material & $\mathrm{Cu}$ & $\mathrm{Cu}$ & $\mathrm{Cu}$ & $\mathrm{Al}$ \\
\hline
\end{tabular}

of the vapor chamber deduced in this study in the calculation of its vapor chamber, which signifies a substantial contribution to the thermal-module industry.

\section{CONCLUSION}

Thermal-performance of the thermal module with the vapor chamber can be determined within several seconds using the window program VCTM V1.0 and the final formula deduced in this article. This study answered how to evaluate the thermal-performance of vapor chamber-based thermal module application in high-performance servers. The main conclusions of this study can be summarized as follows:

1. The effective thermal conductivities of vapor chamber is many times higher than that of the copper and aluminum heat spreaders, proving that it can effectively reduce the temperature of heat sources.

2. The maximum heat flux of the vapor chamber is over 100 $\mathrm{W} / \mathrm{cm}^{2}$, and its effective thermal conductivity will increase with increased input power.

3. It is deduced from the novel formula that the maximum effective thermal conductivity is $870 \mathrm{~W} / \mathrm{m}^{\circ} \mathrm{C}$, and comparing it with the experimental value, the calculating error is no more than $\pm 3 \%$.

4. From the results of the thermal-performance experiment, one- and two-dimensional thermal conductivities of the vapor chamber is about $100 \mathrm{~W} / \mathrm{m}^{\circ} \mathrm{C}$, less than that of most single solid-phase metals.

5. Three-dimensional thermal conductivity of the vapor chamber is up to $870 \mathrm{~W} / \mathrm{m}^{\circ} \mathrm{C}$, many times than that of pure copper base plate.

6. The effective thermal conductivities of the vapor chamber is closely relate to its dimensions and heat-source flux. In the case of small-area vapor chamber and small heat-source flux, the effective thermal conductivity is less than that of pure copper material.

7. The average error in calculating the thermal-module performance of the vapor chamber by use of the inferred formula of the effective thermal conductivity in this article is no less than $\pm 3 \%$.

8. The HP and IBM blade system thermal module using vapor chamber-based thermal module shows superior thermal performance comparing to traditional thermal modules. So, the vapor chamber thermal cooler is the best thermal solution for the high-performance servers. 


\section{ACKNOWLEDGMENTS}

The authors gratefully acknowledgment the financial support from NTOU and NSC 97-2218-E-019-003 for the present study.

\section{NOMENCLATURE}

A Area of the vapor chamber, $\mathrm{m}^{2}$

$L \quad$ Length of the vapor chamber, $\mathrm{m}$

$T$ Temperature, ${ }^{\circ} \mathrm{C}$

$W \quad$ Width of the vapor chamber, $\mathrm{m}$

$k$ Thermal conductivity, $\mathrm{W} / \mathrm{m}^{\circ} \mathrm{C}$

$t \quad$ Thickness of the vapor chamber, $\mathrm{m}$

$P_{s} \quad$ Saturated vapor pressure, $\mathrm{N} / \mathrm{m}$

$R_{t} \quad$ Total thermal resistance, ${ }^{\circ} \mathrm{C} / \mathrm{W}$

$q_{\text {in }} \quad$ Input power, $\mathrm{W} / \mathrm{m}$

$h_{f g} \quad$ Latent heat of working fluid, $\mathrm{J} / \mathrm{k}$

$\phi h$ Height of working fluid inside the vapor chamber, $\mathrm{m}$

\section{$\underline{\text { Subscripts }}$}

\begin{tabular}{ll}
\hline$a$ & Ambient \\
$b$ & Base of the vapor chamber \\
$h$ & Heat source \\
$w$ & Wick structure \\
$d a$ & Mean Lower surface temperature of the vapor chamber \\
$d c$ & Lower central surface temperature of the vapor chamber \\
$u a$ & Mean upper surface temperature of the vapor chamber \\
$u c$ & Upper central surface temperature of the vapor chamber \\
$v c$ & Vapor chamber \\
$e f f$ & Effective
\end{tabular}

\section{REFERENCES}

1. Beaton, C. and Hewitt, G., Physical Property Data for the Design Engineer, Hemisphere, New York (1989).

2. Chen, Y. S., Chien, K. H., Hung, T. C., Wang, C. C., Feng, Y. M., and Pei, B. S., "Numerical simulation of a heat sink embedded with a vapor chamber and calculation of effective thermal conductivity of a vapor chamber," Applied Thermal Engineering, Vol. 29, No. 13, pp. 2655-2664 (2009).

3. Hsieh, S. S., Lee, R. Y., Shyu, J. C., and Chen, S. W., "Thermal performance of flat vapor chamber heat spreader," Energy Conversion and Management, Vol. 49, No. 6, pp. 1774-1784 (2008).

4. Koito, Y., Imura, H., Mochizuki, M., Saito, Y., and Torii, S., "Fundamental experiments and numerical analyses on heat transfer characteristics of a vapor chamber (Effect of heat source size)," JSME International Journal, Series B, Vol. 49, No. 4, pp. 1233-1240 (2006).

5. Lefevre, F. and Lallemand, M., "Coupled thermal and hydrodynamic models of flat micro heat pipes for the cooling of multiple electronic components," International Journal of Heat and Mass Transfer, Vol. 49, pp. 1375-1383 (2006).

6. Lin, J. C., Wu, J. C., Yen, C. T., and Yang, C. Y., "Fabrication and performance analysis of metallic micro heat spreader for CPU," 13th International Heat Pipe Conference, Shanghai, China, pp. 21-25 (2004).

7. Wang, J. C., "Superposition method to investigate the thermal performance of heat sink with embedded heat pipes," International Communications in Heat and Mass Transfer, Vol. 36, No. 7, pp. 686-692 (2009).

8. Wang, J. C., "Development of vapour chamber-based VGA thermal module," International Journal of Numerical Methods for Heat \& Fluid Flow, Vol. 20, No. 4, pp. 416-428 (2010).

9. Wang, J. C., Wang, R. T., Chang, C. C., and Huang, C. L., "Program for rapid computation of the thermal performance of a heat sink with embedded heat pipes," Journal of the Chinese Society of Mechanical Engineers, Vol. 31, No. 1, pp. 21-28 (2010).

10. Wei, J., "Challenges in cooling design of CPU packages for high-performance servers," Heat Transfer Engineering, Vol. 29, No. 2, pp. 178187 (2006). 